\title{
Rich Pictures: Non Visual use of Visual Tools
}

\author{
Ronald Macintyre
}

\section{RoughBounds Consulting, United Kingdom}

\begin{abstract}
:
This reflective article explores the use of Soft Systems Methodology (SSM) Rich Pictures within the learning design. It introduces SSM as part of a broader interest in systems within education and positions SSM as part of a broader family of participatory approaches within a range of fields. Based on learning design practice with organisations looking to (re)connect with learners, the paper sets out a scenario where participants are asked to draw of a Rich Picture of the "ideal learner", where questions of future selves and ideal forms highlight are used to highlight the nonrepresentative nature of representative forms. It reflects on questions of power on deliberative decision-making tools like Rich Pictures and suggests ways of addressing this in practice. It argues that care needs to be taken lest the value of Rich Pictures is the visual representations made rather than the process, and suggests that practitioners should remember that the image is not the outcome.
\end{abstract}

Keywords: Participatory Design; Online Learning; Rich Pictures 


\section{Introduction}

This short practice paper explores the use of "Rich Pictures" a tool developed by Peter Checkland as part of a broader set of what are called Soft Systems Methodologies (SSM). In this reflective paper, SSM is set out as part of the development of a "personal theory of practice" (Jarvis, 1999). The paper starts with an overview of SSM and sets out my engagement with SSM as part of a family of approaches to participatory research and design. It then looks at Rich Pictures, a visual tool used to structure deliberative decision making developed by Checkland as part of SSM. The paper lays out a scenario where Rich Pictures is employed to help people (re)connect with learners as part of a learning design process and highlights several issues with Rich Pictures. The paper concludes with some further reflections and emphasises the need to interrogate the assumptions within the tools we use.

\section{Soft Systems and Learning Design}

There is a tradition in educational research of thinking of learning as a system. The application of systems thinking ranges from radical pedagogies and Apple's (2004) examination of curriculum and power to the application of Bourdieu work on social distinction was a way to explore systemic structural issues around inclusion (Bathmaker, Ingram and Waller, 2013). There has also been an interest in systems theorist like Grannovetter (1973) and how they might be used to examine online learning communities (Macintyre and Macdonald, 2011). Along with interest in Latour's Actor-Network Theory to examine socio-material/technical relationships in learning (Fenwick and Edwards, 2010). Given that educational issues are often practical ones and solved through "doing something" (Kemmis, 2010), then it is not surprising that taking those actions involves thinking systemically and this has become a routine way for education action researchers to think. Likewise, many SSM approaches are also routinely used by facilitators, even if they are not named as such. Spray Diagrams (Mind Maps), Influence Diagrams, Multiple Cause Diagrams and so on are all part of the way people work with others to address issues. The paper is not about SSM, to learn more about SSM and its different approaches this free course from the Open University is a good place to start - see Open University (2018). However, it is worth looking at the origins of these familiar tools.

SSM is a family of approaches to problem-solving and the understanding of social issues systemically. SSM's use is common on applied subjects (engineering, technology health and social care) and its origins are in sciences, with the term soft used to emphasise that these are not technical issues with clear technical solutions. SSM deals with issues that do not involve simple causal relations but more complex social systems. SSM is used in systems, where it is difficult to agree on the nature of the issue or problem. As such SSM overlaps significantly with work on "Wicked Problems", and the development of "Clumsy Solutions" (Buchanan, 1992). Checkland was one of the originators of SSM, a chemist, he worked in industry before becoming an academic first at Lancaster and then later at the Open University (OU). Checkland's background in Industrial Chemistry is relevant. Chemists like models and visualisations and use them to set out and explore complex causal relations in a way

International Journal of Management and Applied Research, 2020, Vol. 7, No. 3 
that they and others can understand (Crombie, 1995). The experience in the industry, where hard systems (like how to manufacture a chemical) combine with soft systems (human resources, political regulation, environmental concerns) as an organisation looks to take a chemical process and do them at scale speak to overlapping types of complexity. It speaks to what people in SSM call messes; these are complex issues where technical complexity overlaps with social complexity (Brydon-Miller, Greenwood and Maguire, 2003).

My interest in SSM arose from working with different kind of messes but messes nonetheless. It was my work in community development and participatory design, with SSM part of a broader family of tools and techniques to encourage participation that emerged in the 1970s and has become part of the participatory toolkit (Robertson and Simonsen, 2012). I took this interest with me when I crossed over into Higher Education outreach and Widening Participation (WP). Influenced by Lane's work on education (see Lane 2013; 2019), I incorporated SSM into my educational action research and learning design practice. Specifically, I started to use it as a way to bring new voices into the curriculum. First of all as part of the design free online learning resources (Open Educational Resources or OER, e.g. Macintyre, 2013) with groups outside the academy and later supporting organisation to develop online learning (Cannell and Macintyre, 2017).

Learning design, in particular in online and blended contexts in which I operate involves the combination of different ways of working. It involves creating a space between existing technical systems like Learning Management Systems and Virtual Learning Environments which shape and are shaped by human systems (see Feenberg, 2002), and the knowledge systems and routines associated with the way we do things around here (Nonaka, 1994). In addition, there is the subject and its pedagogy and the need to include learners voices in order to develop materials that meet the needs of learners. It is messy, and education practitioners walking the edges of the organisational norms (in OER or WP) need to work through these complex relations as part of developing their ways of working. SSM encourages people to look at the connections and the whole, and this means going beyond recognising something as a system to thinking about an issue as being systemic (Burns, 2014). Rich Pictures is a crucial component within this holistic approach. The next section sets out an approach to Rich Pictures, which draws on Checkland. However it is important to note that Checkland never set out Rich Pictures in a definitive way as part of SSM; instead, it evolved in his work and the work of other practitioners (Bell and Morse, 2010).

\section{Using Rich Pictures}

On a practical level Rich Pictures involves a group coming together around a shared and often unclear issue, the idea is that large sheets of paper and a selection of pens are placed on a table in the middle of a (not too large, not too small, two to six) group. The participants are presented with an issue and asked to draw a representation of the issue. Checkland (1981) emphasises that words are not appropriate; people need to illustrate ideas through drawing pictures. The pictorial element, where something is picked to represent something else is essential because the conversation about what is an

International Journal of Management and Applied Research, 2020, Vol. 7, No. 3 
appropriate metaphor or image to represent something is part of group sense-making. Participants are asked to talk before they draw, share the pen and come to a shared view or consensus on what goes onto the paper.

One of the issues with Rich Pictures is that the very thing that makes it useful, a shared understanding of an issue or the beginnings of a solution may be the biggest problem with its use. Consensus is typically seen to be a good thing, and an essential part of the decision-making process, something that is required in order that everyone can move forward. Work on consensus building can be found in Change Management (Diamond and Rush, 2012), on discourses in politics the Public Sphere (Habermas, 1991), and in design work (Green, Southee and Boult, 2014). For example, the UK Design Councils "Double Diamond design models emphasise the need to manage a transition from a divergent idea generation phase to a convergent decision-making stage. For example, The UK Design Council (2020) has recently updated its "Double Diamond" however the principles of overlapping phases of divergent (idea generation discover and develop) and convergent (decision making defining and delivering) remain the same.

However, care needs to be taken over that transition between these phases, in particular over uneven power relations due to social structural or organisational inequalities. Participatory design is sensitive to these power relations and risk of forcing consensus, some participatory designers noting the importance of dissensus and the need for voices to challenge dominant narratives (Le Dantec and Disalvo, 2013). Political theorists have also challenged the idea of managed consensus, noting the careful curation of public opinion and the importance of what is often terms counter publics in raising issues around gender, sexuality race and ethnicity (Hauser and Benoit-barne, 2002; Warner, 2002; Fraser, 2010).

The sense of consensus as a strength and a weakness of Rich Pictures informs my practice. Participatory design work can only proceed through consensus. Nevertheless, the transition to this position is fraught, Rich Pictures key instruction, which is to agree on what goes down on the page, may end up promoting particular narratives over others. As a facilitator, it is essential to be mindful of the potential for a group exercise to recapitulate existing power relationships. With this in mind, my approach to Rich Pictures is to bend the approach, using it to create a broad frame that accepts difference. In order to demonstrate this, I share an example from my practice. It is based on an exercise I conduct in order to help organisations (re)connect with learners.

\section{Imagine the Ideal Learner}

The exercise assumes that when you design a learning journey; you are designing something that is about transformation. However, the transformation is through and then at the end of the journey, and this means learning design is about the future. The approach I set out here is based on working with applied disciplines, where learning for in for and through doing. For me, this involves working with academics, practicebased experts and learners to develop learning materials. Therefore the way I describe "Rich Pictures" here is based on working in this context. However, as noted in the previous section, I have applied it in other contexts in the past with some success.

International Journal of Management and Applied Research, 2020, Vol. 7, No. 3 
In my design practice, I start at the end, with what the learner will be able to do in the world once they have completed the course that they are not able to do now. To do this, I draw on the Platonic concept of the ideal form. Plato's theory of forms suggested that there is an ideal form (Plato, 1986). Plato suggests we imagine people who live in caves and only see things has shadows on the wall cast by the fire. The world is but mere shadow, a representation of a form that we cannot perceive. The ideal is useful because (like the image people are asked to draw) it is a representation. In this case, I ask the group to think about their ideal learner; sometimes I only focus on who they will be at the end, sometimes I ask the participants to start with who their ideal learner will be at the end and trace out there journey to that point. It largely depends on the context, and sometimes I follow one with the other.

For the participants, the activity is framed in relation to the ideal outcome for the learner; my frame is based on the two main ways in which we imagine the future. The first one involves making predictions of the future based on careful modelling of current trends, in Europe, this tends to be called Foresight (in the US it is Futurology). Foresight is one of the most common approaches in work where policy orientates research around "real-world problems" (Nowotny, Scott and Gibbons, 2003). For example, the UK Government has a Foresight and publication, see here https://foresightprojects.blog.gov.uk/, and we are surrounded by those approaches to imaging and predicting future events. At the time and place of writing (August 2020 in the Highlands of Scotland) the most obvious are models associated with COVID-19 and the heatwave across Europe linked to climate change. Alternatively, there are speculative approaches to the future; these speculative approaches attempt to free themselves of the present and create visions of a future set of possibilities (sometimes positive visions, sometimes negative ones).

Speculative futures may not be based on predictive modelling of the present. However, speculative futures aim to create plausible visions of the future in order to influence our behaviour in the present (Auger, 2013; Malpass, 2016). Examples might include the way an artist or even an advertising claim depicts the catastrophic impact of climate change. For example, a 2019 art installation by Niittyvitra and Aho in Western Isles of Scotland used lines of light on the buildings and the landscapes of the low lying Uists to set out new sea levels associated with climate change - see here http://www.niittyvirta.com/lines-57-59-n-7-16w/ .

In my experience when people think about futures, they often engage in a mix of Foresight (using the present to model the future) and speculation (thinking about the future to look at the present), and it is the same in learning design. Asking people to think about the future performs a similar function to the ideal form, in that participants are not asked to represent existing social and structural relations directly but imagine future ones, it helps separate the representation from the real.

As Bell and Morse (2010) note an image can often take on a power itself, and the critical element of Rich Pictures, to represent complex ideas as an image that they cannot easily put into words, seems to imbue the image with a quasi-mystic power. In

International Journal of Management and Applied Research, 2020, Vol. 7, No. 3 
my practice, I depart from many approaches to Rich Pictures, which analyse the image and instead focus on the discussion. The approach is informed by the work of critical theorists on deliberative decision making (e.g. Fraser, 2010; Warner, 2002), who suggests a need to listen to; who claims the power to make connections, how the connections are made and what is being connected. Noting the way articulation between elements in deliberative discourses privilege some forms of knowledge and people over others and that once connections are made, they are challenging to unmake (Laclau and Mouffee, 1985).

As a facilitator, one of the crucial things to remember is that in Rich Picture, the picture does not matter, as it is the discussions about the picture that is of interest to the facilitator. So when I listen to people created a Rich Picture of a learners outcomes or a learners journey, I listen to the ways they throw themselves into the future as a clue to how they think about the present. Over the years, I have observed that the ideal learner is based on personal experience and organisational capacity. At a personal level, it draws on images of themselves as learners, and the kinds of learners they like to engage with, with participants sharing their experience in order to legitimate a particular perspective. Organisationally, the ideal learner is often a conversation about the kinds of learner the organisation is set up to support. So the description of the learner often tells the facilitator what the person thinks the organisation is good at and what it does not do well.

As well as listening to the conversations about personal and organisation views of the ideal learner the third area I listen for is the chat about the "actual learner". It can be challenging for people to think about ideal scenarios, and often people spend a lot of the session talking about the actual learners. They do this by sharing experiences of their teaching practice or learning experience, what works what does not work, and again what the organisation does to address issues, or what the organisation cannot or will not do. What asking people to think about an ideal future does is to focus their attention on the present, with speculations about possible futures leading to people question social and structural relations in the present.

As participants throw themselves into the future they talk about what they might draw, they share the pen, they laugh, sometimes argue, meanwhile as a facilitator I am listening, weaving together narratives, setting out counterfactual or alternative visions to provoke. All this is part of making a Rich Picture. I do encourage people to break away from the Rick Picture convention, and sketch out tensions and disagreements, to set out dissensus. However, in my experience, the picture itself, which is meant to represent a shared view, is not important at all, and this is why I have not included any examples in this article. For an approach to Rich Pictures that is closer to Checkland (1981) and more in keeping with the analysis of the image approach suggested by Bell and Morse (2010), it is worth looking at this suite of free videos about Rich Pictures where Bell, Morse and a range of other talks about SSM and Rich Pictures - see Open University (2012).

Initially, I was much closer to the position set out by Checkland (1981) and advocates like Bell and Morse (2010), and very much focussed on the image. Over time I have

International Journal of Management and Applied Research, 2020, Vol. 7, No. 3 
come to realise that Rich Pictures is useful to me as a practitioner when I recognise the image is not the outcome, the outcome is the process, and the process is the outcome. It is the use of drawing and asking people to reach a consensus while creating a space where they surface hidden assumptions and engage in shared sense-making that is the crucial thing. In that sense, Rich Picture makes use of ocularcentrism, and the way images beguile us but is also a counterpoint to the privileging of the visual (see Pallasma, 2005). However, it only provides this counterpoint if practitioners can wrestle themselves away from the apparent fixity of the image. After all, the image is a representation of a process, and behind the apparent fixity of the visual are interpretations that vary temporally and spatially (Clark, 2006).

\section{Conclusion}

SSM is best viewed as part of a family of approaches to dealing with complex problems and encouraging participatory decision making that emerged in the 1970s. While there is disciplinary interest in SSM (e.g. Business and Management) and institutional interest (The Open University and the University of Lancaster) in my experience SSM type approaches are used but not named. Effectively SSM and derivations of SSM systems mapping tools have become embedded in the facilitation of group sense-making. Highlighting them here is not an attempt to get people to name and use SSM as part of their practice. Approaches should adapt and change over time, and often for a good reason. For example, without due care, Rich Pictures has the potential to reify existing power relations by pushing participants to a consensus. Uneven participation and the addressing underlying social and structural inequalities is a challenge for all deliberative decision-making process, and facilitators in participatory models have wrestled with the challenge for some time (Bjögvinsson, Ehn and Hillgren, 2012).

The first step in addressing the challenge involves recognising it is a challenge. Understanding the nature of the challenge means an interrogation of the assumptions within an approach. SSM is a way of thinking about messes that can help participants to make sense of them. SSM understands these messes as arising from a layering of technical and social complexity and accepts that messy problems have clumsy solutions (Brydon-Miller, Greenwood and Maguire, 2003). The clumsiness of the solution is important; the assumption in SSM is that there is a range of possible solutions and that these solutions are themselves unstable. The second assumption is that we can abstract our experience of the "real world" and represent it as a system and treat complex open systems with multiple connections "as if" they are closed systems that we can map and understand. I have found using ideal forms in the future helps remind people of the representational and discursive nature of the images.

Creating these boundaries around a mess and choosing appropriate abstractions involves making decisions. In Rich Pictures, these are deliberative decisions based on a consensual view. Understanding the assumptions within the approach reemphasises the need to listen to what is said about what is drawn. In SSM, those assumptions are understood in relation to CATWOE (Customer/Who, Actors/Stakeholders, Transformation, Weltanschauung/Worldview, Owners, Environmental Constraints, see

International Journal of Management and Applied Research, 2020, Vol. 7, No. 3 
Checkland, 1981). Certainly, this has informed my practice, but ever cautious of the dangers of consensus and challenges in participatory approaches for me, critical theory is also essential (e.g. Fraser, 2010). As a facilitator, this means focussing on the process and taking careful notes. It also means engaging with participants and asking questions posing challenges but also paying attention to what is not said, what does not make it onto the paper, to how and what gets abstracted, the articulation of elements and the boundary-making practices of the group.

This practice article sets SSM in the context of a broader interest in systems, it suggests that Rich Pictures should be viewed in relation to a broader family of participatory approaches and points out a range of problems that can arise when using Rich Pictures. Problems that might arise if the assumptions within SSM and Rich Pictures are not adequately addressed through careful facilitation. Of course, these are challenges for any deliberative decision-making tool, but in my experience, they are often accentuated in visual approaches. When people put pen to paper and make something, the thing that is made often becomes the outcome, and I have made this mistake and treated the picture as something to be analysed (see Macintyre, 2014). The critical thing to remember about Rich Pictures is that the image is not the outcome.

\section{References}

1. Auger, J. (2013), "Speculative design: Crafting the speculation", Digital Creativity, Vol. 24, No. 1, pp. 11-35. https://doi.org/10.1080/14626268.2013.767276

2. Bathmaker, A.-M., Ingram, N. and Waller, R. (2013), "Higher education, social class and the mobilisation of capitals: recognising and playing the game", British Journal of Sociology of Education. Vol. 34, No. 5-6, pp. 723-743. https://doi.org/10.1080/01425692.2013.816041

3. Bjögvinsson, E., Ehn, P. and Hillgren, P. A. (2012), "Design things and design thinking: Contemporary participatory design challenges", Design Issues, Vol. 28, No. 3, pp. 101-116. https://doi.org/10.1162/DESI_a_00165

4. Brydon-Miller, M., Greenwood, D. and Maguire, P. (2003), "Why Action Research?", Action Research, Vol. 1, No. 1, pp. 9-28. https://doi.org/10.1177/14767503030011002

5. Buchanan, R. (1992), "Wicked Problems in Design Thinking", Design Issues, Vol. 8, No. 2, pp. 5-21.

6. Burns, D. (2014), "Systemic action research: Changing system dynamics to support sustainable change", Action Research, Vol. 12, No. 1, pp. 3-18. https://doi.org/10.1177/1476750313513910

7. Cannell, P. and Macintyre, R. (2017), "Free open online resources in workplace and community settings - a case study on overcoming barriers", Widening Participation and Lifelong Learning, Vol. 19, No. 1, pp. 111-122. https://doi.org/10.5456/WPLL.19.1.111

8. Checkland, P. (1981), Systems Thinking, Systems Practice. Chichester: John Wiley and Sons.

International Journal of Management and Applied Research, 2020, Vol. 7, No. 3 
9. Clark T. J. (2006), The Sight of Death: An Experiment in Art Writing, London: Yale University Press.

10. Crombie, A. C. (1995), "Commitments and Styles of European Scientific Thinking", History of Science, Vol. 33, No. 2, pp. 225-238. https://doi.org/10.1177\%2F007327539503300204

11. Le Dantec, C. A. and Disalvo, C. (2013), "Infrastructuring and the formation of publics in participatory design”, Social Studies of Science, Vol. 43, No. 2, pp. 241264. https://doi.org/10.1177/0306312712471581

12. Diamond, J. and Rush, L. (2012), "Intra-organisational collaboration in one UK university: Potential for change or missed opportunity", International Journal of Public Sector Management, Vol. 25 No. 4, pp. 287-300. https://doi.org/10.1108/09513551211244115

13. Feenberg A. (2002), Transforming Technology: A Critical Theory Revisited, Oxford: Oxford University Press.

14. Fenwick T. Edwards R. (2010), Actor-Network Theory in Education, London: Routledge.

15. Fraser, N. (2010), "Who Counts? Dilemmas of Justice in a Postwestphalian World", Antipode, Vol. 41, No. S1, pp. 281-297 pp. 281-297. https://doi.org/10.1111/j.1467-8330.2009.00726.x

16. Granovetter, M. (1973), "The Strength of Weak Ties", American Journal of Sociology, Vol. 78, No. 6, pp. 1360-1380. https://doi.org/10.1086/225469

17. Green, S., Southee, D. and Boult, J. (2014), “Towards a Design Process Ontology”, The Design Journal, Vol. 17, No. 4, pp. 515-537. https://doi.org/10.2752/175630614X14056185480032

18. Habermas, J. (1991), The Structural Transformation of the Public Sphere An Inquiry into a Category of Bourgeois Society, translated by Burger, T. and Lawrence, F., Cambridge, Mass.: MIT Press

19. Hauser, G. A. and Benoit-barne, C. (2002), "Reflections on rhetoric, deliberative democracy, civil society, and trust", Rhetoric and Public Affairs, Vol. 5, No. 2, pp. 261-275. https://doi.org/10.1353/rap.2002.0029

20. Jarvis, P. (1999), The Practitioner Researcher: Developing Theory from Practice, San Francisco: Jossey Bass.

21. Kemmis, S. (2010), "What is to be done? The place of action research", Educational Action Research, Vol. 18, No. 4, pp. 417-427. https://doi.org/10.1080/09650792.2010.524745

22. Laclau E. and Mouffee C. (1985), Hegemony and Socialist Strategy: Towards a Radical Democratic Politics, Verso: London

23. Macintyre, R. and Macdonald, J. R. (2011), "Remote from what? Perspectives of distance learning students in remote rural areas of Scotland", International Review of Research in Open and Distance Learning, Vol. 12, No. 4, pp. 1-16. https://doi.org/10.19173/irrodl.v12i4.847

International Journal of Management and Applied Research, 2020, Vol. 7, No. 3 
24. Macintyre, R. (2013) 'Open Educational Partnerships and Collective Learning', Journal of Interactive Media in Education, Vol. 2013, No. 3, Article 20. https://doi.org/10.5334/2013-20

25. Macintyre, R. (2014), "Uncertainty, learning design, and interdisciplinarity: systems and design thinking in the school classroom", In: 4th International Conference Designs for Learning: Expanding the Field, 6 -9 May 2014, Stockholm.

26. Malpass, M. (2016), "Critical Design Practice: Theoretical Perspectives and Methods of Engagement", Design Journal, Vol. 19, No. 3, pp. 473-489. https://doi.org/10.1080/14606925.2016.1161943

27. Nonaka, I. (1994), “A Dynamic Theory of Organizational Knowledge Creation”, Organization Science, Vol. 5, No. 1, pp. 14-37. https://doi.org/10.1287/orsc.5.1.14

28. Nowotny, H., Scott, P. and Gibbons, M. (2003), "Introduction: 'Mode 2' Revisited: The New Production of Knowledge", Minerva, Vol. 41, No. 3, pp. 179-194. https://doi.org/10.1023/A:1025505528250

29. Open University (2012), The Art of Rich Pictures: Track 1, UK: Open University. Available from: https://www.open.edu/openlearn/science-mathstechnology/engineering-technology/the-art-rich-pictures[Accessed on 29 July 2020].

30. Open University (2018), Mastering systems thinking in practice, UK: Open University. Available from: https://www.open.edu/openlearn/science-mathstechnology/mastering-systems-thinking-practice/content-section-overview?activetab=content-tab [Accessed on 29 July 2020].

31. Plato (1986), The Republic, London: Penguin Classics.

32. Pallasma J. (2005), The Eyes of the Skin: Architecture and the Senses, Chichester: John Wiley and Sons.

33. Robertson, T. and Simonsen, J. (2012), "Challenges and opportunities in contemporary participatory design”, Design Issues, Vol. 28, No. 3, pp. 3-9. https://doi.org/10.1162/DESI_a_00157

34. Warner, M. (2002), "Publics and Counterpublics", Public Culture, Vol. 14, No. 1, pp. 49-90. https://doi.org/10.1215/08992363-14-1-49

35. UK Design Council (2020), Double Diamonds for 15 years. [Video] Available from: $\quad$ https://www.designcouncil.org.uk/news-opinion/double-diamond-15-years [Accessed on 29 July 2020].

International Journal of Management and Applied Research, 2020, Vol. 7, No. 3 